\title{
MEMÓRIA ANCESTRAL e o Brasil contemporâneo - Tradição junguiana e o inconsciente brasileiro
}

\author{
Nleš Vrbata (UEF'S/CADES/PNDD) \\ Claudio Cledson Novaes (Orientador-ULFE)
}

(...) tanto uma pessoa como uma coletividade em certos momentos se vêem estimuladas a desenvolver seu lado superior. Só que no Brasil é muito complicado desenvolver o lado das virtudes e das qualidades. Coletivamente, não há nem estímulo nem momento para isso. Acho que se fez um certo pacto no plano social permitindo que a inferioridade se instalasse e ficasse lá (1999, p. 151)

Os estudos culturais brasileiros, crítica literária, história, sociologia e outras disciplinas trabalham há muito tempo com a formação do imaginário brasileiro. Clássicos como Sérgio Buarque de Holanda ou Gilberto Freyre ou autores contemporâneos como Silviano Santiago ou José Murilo de Carvalho, que apresentam perspectivas quanto à identidade nacional brasileira, ou caráter nacional do Brasil. Aspectos da psicologia junguiana ajudam na abordagem desse tópico, a partir do inconsciente coletivo, mas também a partir do conceito do complexo cultural. Enquanto o romantismo brasileiro, e mais tarde o modernismo, construiu e ideologizou a história brasileira e a identidade nacional, a tradição junguiana as psicologiza e não se esforça na oficializaçáo das teses destas. Foi provavelmente Gambini quem introduziu a ideia da "psiquização da história”. Para ele "há um preconceito contra a vida psíquica e há um preconceito contra a psiquização da história. Não é científico fazer fantasias. Mas (...) a nossa história é toda elaborada em cima de fantasias, desde o começo" (GAMBINI:1999, p.18). 
A oficialização e a ideologização de um certo imaginário foram sempre ligadas com a natureza do regime político de um país determinado. No fim dos anos 80 foi elaborado um conceito de culture wars nos EUA. Este conceito tratou da questáo de oficializaçấo do imaginário nacional e substituiu o conceito de Benedict Anderson, o de imagined communities e "provides the tools necessary to explore the actual forums and the local politics of the national imagery" (WILLIAMS:2001, p.22). Culture wars consiste no estudo:

[of] the fight for nationhood taking place within state-sponsored cultural venues. The imprimatur of state patronage—no matter how indirect, or how symbolic — pits competing constituencies against one another for control of objects and exhibition spaces that they claim to harbor and protect the national ethos (WILLIAMS:2001, p. 24) ${ }^{1}$.

Daryle William aplicou o conceito de culture wars à história da política cultural brasileira e constatou a importância extraordinária do padrão cultural para a cultura nacional. A culture wars brasileira foi feita "not just the definition of good and bad art, but rather the consecration of good and bad Brazilian art and the enthronement of dominant cultural brokers willing to protect and defend their cultural positions in the name of protecting national culture" (WILLIAMS:2001, p. 21).

Enquanto estudos acima mencionados ficam concentrados ao nível empírico da cultura e da política cultural, não se ocuparam da psiquização da cultura, mas antes da ideologização e oficialização dela.

O conceito do complexo cultural não interpreta os fenômenos sociais de massa referindo-se exclusivamente ao arquétipo, mas leva em consideração os fatores sociais, políticos, econômicos e outros. É concebido como o foco vivo da energia psíquica e como qualquer outro complexo faz parte do processo da evolução permanente do inconsciente coletivo. Não deveriamos confudi-lo com o caráter nacional ou a identidade nacional:

Cultural complexes are not the same as cultural identity or what has sometimes been called "national character", although there are times when cultural complexes, cultural identity and national character can seem impossibly intertwined. (...) (SINGER-KIMBLES:2004, p. 5)

Tanto nas sociedades quanto nas culturas esses complexos existem durante os séculos e milhares de anos. Os estereótipos, preconceitos, piadas, padrões, atitudes, opinôes coletivas são solidamente enraizados na coletividade compartilhada num complexo. 
Se Gambini escreve sobre o "feminino esvaziado" ou sobre a "aventura fálica", "genocídio" ou da negação da cultura indígena e africana, não os entende como fenomenos exteriores, mas sim como fenomenos psiquicos coletivos cuja realidade continua vivendo no inconsciente coletivo. Segundo Gambini, esses eventos constituem os monumentos fundadores do pais e que dominam o inconsciente coletivo brasileiro.

\section{Perspectiva junguiana: imaginários brasileiros}

Na sua tese de dissertação no C.G. Jung Institute (Zürich) Gambini analisou a correspondência jesuita entre a colonia brasileira e Lisboa para identificar a transferência psicologia dos jesuita e " $o(s)$ outro(s)", i.e. o imaginario que o catolico europeu passou à terra brasileira e aos seus habitantes e consequentemente a condiçáo psicologica e arquetipica da "alma brasileira" e os complexos culturais principais brasileiros. Gambini tentou entender a psicopatologia coletiva brasileira a partir dos principais arquetipos/ complexos culturais e a participaçáo deles na patologia social do Brasil contemporâneo. Não trabalha com o conceito do "complexo cultural", mas é na verdade ele quem importou esse conceito aos estudos junguianos brasileiros.

Para Gambini "o encontro das civilizaçôes" no século XVI deveria ser concebido em termos do simbolismo alquímico "coniunctio oppositorum" (conjunçáo dos opostos) do C. G. Jung no volume 14 da Obra completa ${ }^{2}$. Conforme a essa perspectiva, este evento histórico foi uma ocasiáo extraordinária do encontro não só das raças, dos sexos e da religião, mas principalmente das imagens e imaginários dos protagonistas envolvidos. A ênfase posta em imaginário não é uma coincidência. $\mathrm{O}$ interesse principal pelo fenómeno social-patológico na sociedade contemporânea brasileira leva Gambini a investigar a origem dele através do imaginário da mitologia "oficial" e "obscura". No seu ver, a alma brasileira nasceu das projeçôes mutuas coletivas dos conquistadores e dos conquistados e por isso o Brasil testemunhou o que ele chama de "desencontro imaginal": na imaginacáo de ambos protagonistas "o outro" se manifestava numa forma radicalmente distorcida. Por isso Gambini fala também da "negação cultural". Segundo Gambini estas "negaçôes" e "desencontros" constituem a base do inconsciente da cultura brasileira contemporânea por excelência, determinam a formação dela e são fortemente presentes na psicologia coletiva ainda hoje. Enquanto o consciente coletivo brasileiro e a ideologia oficial interpretam a história nacional frequentemente da perspectiva europeia, muitos outros aspectos continuam sendo ignorados, não refletidos e ficam fora do discurso oficial.

Acessar o inconsciente coletivo é possível através das imagens socialmente compartilhadas mas nomeadamente aquelas que decorrem daquela parte da historia que 
continua sendo ignorada, rejeitada, não reconhecida, soterrada. Isso é o lugar onde começou a colaboração entre psicologia analítica (junguiana) e história já antes da Segunda Guerra Mundial. A melhor manifestação desta tendência constitui o historiador Arnold J. Toynbee ou a psicohistória do psicólogo Erik Erikson (MEYER:2007). Segundo Gambini "Há uma questão teórica importante que alguns antropólogos, sociólogos e historiadores têm discutido nas últimas décadas (...) para explicar a história é preciso levar em conta o imaginário. (...) (GAMBINI 1999:142).

Segundo Gambini a formação social, política e sociológica do Brasil foi analisada suficientemente, mas a perspectiva psicológica não foi levada em consideração. A perspectiva arquetípica reconhece a primazia epistemológica do imaginário e assim acessa as camadas mais profundas da psique coletiva brasileira. Como a história do país e o inconsciente coletivo do país são inseparáveis, Gambini acredita numa conexão profunda dos dois até agora reconhecida. Para ele a história esgotou abordagens que já são ultrapassadas: "hoje não se encara mais a história só como resultado dos fatores econômicos, como é a visão marxista, ou a história feita pelas guerras”. Se a história pretende provocar as mudanças na sociedade brasileira, tem que levar com consideração o imaginário coletivo: "essas imagens, os mitos, o imaginário enfim, ficam tão fortes que criam comportamentos e geram mudanças" (DIAS- GAMBINI:1999, p.142). Gambini acredita que a psicologia pode levar nossas análises mais profundo do que as ciências sociais:

Ele [Jung] dizia claramente: 'Eu não acredito na revoluçáo social, só acredito na revolução individual como primeiro passo.' Mas, de fato, o que prevaleceu foi a outra visão, em que entram o marxismo, o positivismo, o liberalismo, as várias correntes ideológicas e políticas que moldaram o século. (DIAS-GAMBINI:1999, p.142-143).

Esta posicão leva Gambini ao estudo de mitos, tradiçôes, estereótipos, padróes e imagens quanto da origem indígena tanto ocidental e principalmente aquelas que foram reprimidas. Assim Gambini tenta penetrar por "caixa-preta do inconsciente brasileiro", por mitologia oficial cultivada pelas ideologias modernas, pelas imagens ideologicamente e culturalmente aprovadas e "refundar a consciência brasileira" (DIAS-GAMBINI:1999, p. 210):

As descobertas da psicanálise (...) afirmam qua há uma história no inconsciente. A pedra angular da psicanálise é poder ter acesso a essa história, que é diferente da história 'oficial' da própria pessoa. Vou falar de caixa-preta. O Brasil é um avião que caiu e precisa achar a caixa-preta (...) (DIAS-GAMBINI 1999, p.82). 


\section{Síntese (im)possível: além do imaginário oficial}

Gambini qualifica como falso e hipócrita o imaginário oficialmente aprovado. Segundo ele algumas realidades brasileiras são sistematicamente disfarçadas. A "Realidade" do país como é vista nas mídias, nas ideologias, na educação e no discurso oficial não corresponde com as camadas mais profundas da psique coletiva brasileira. O mito oficial do país não corresponde com o do verdadeiro passado do Brasil. Segundo Edward Edinger o mito central é uma condição vital para o bem-estar de qualquer sociedade. Isso é justamente o que falta no consciente coletivo brasileiro. Tanto história quanto antropologia nos ensinam, que "human society cannot long survive unless its members are psychologically contained within a central living myth. Such a myth provides the individual his reason for being" (EDINGER, 1977:23).

Também Gambini é convencido de que o consciente coletivo brasileiro não está ligado com as próprias raízes dele. O imaginário oficial está cheio das imagens superficiais e unilaterais, o povo brasileiro carece de mitologia autêntica (sob toneladas de fantasia repousam nossas origens. DIAS, GAMBINI:1999, p. 17) que o ligasse com os raízes dele:

(...) a myth of origin is lacking in our psyche. We are ashamed of our remote past, always regarded as a black hole, a mist, a vague image. We place the official beginning of our history in a magical event called 'The Discovery' — which we know is a false term, a better word for it would be Invasion (...).this fact has serious consequences in what concerns the structuring of our collective consciousness. (...) we deny our ancestral origin (...) (GAMBINI:1998, p.150).

Na visão de Gambini uma das mitologias oficiais brasileras é a mitologia da "síntese" ou da "sincrese" brasileira iniciada pela obra colonizadora portuguesa. O resultado é uma história oficial mal contada que elimina uma grande parte do passado do país. A mitologia oficial é uma romantização do que na verdade ocorreu. Apesar das pesquisas extensivas historiográficas o próprio início do projeto colonizador constitui o que Gambini chama "caixa preta do inconsciente brasileiro" que contem, segundo ele, respostas à questão da identitade brasileira:

(...) this initial historical situation may be felt today as a great loss - and, even more so, as a disassociation. Our conscience and our identity were built on a rational basis and, to complete them, a non-rational counterpart is missing, to sustain the basis, because it was lost right at the beginning of the process that has now been going on for 500 years (GAMBINI:2000, p.19) 
Seguindo a psicologia junguiana Gambini defende a mitologização da história brasileira através do imaginário coletivo como se encontra na criatividade do povo brasileiro desde séculos, segundo ele: "É importante que o Brasil se abra para o exercício da mitologização de suas origens. Isso é ficção, isso é literatura, isso é fantasia, isso é psicologia, é sonho, é intuiçẫo. É o que precisa ser feito" (GAMBINI, 1999, p. 17)

A interpretação do primeiro século da colonização requer uma leitura arquetípica de todo o imaginário associado tanto com o colonizador quanto com o colonizado:

In order to ponder on the issue brought up here, it is necessary to go back to certain subjects, images and symbols that characterize Brazilian history. (...) It is therefore worthwhile to take up certain ideas and images again, that were engrained in all of us since the old school days and to approach them from a new angle (GAMBINI: 2000, p.21)

Mas "a síntese" é palavra geralmente mal-entendida. Segundo Gambini "a síntese" entre culturas e raças ocorreu muito superficialmente e principalmente no nível biológico, mas não no nível psicológico. Em outras palavras, a miscigenacao é um fato empírico enquanto coniunctio é um fenomeno arquetípico, psicológico, i.e. o status ontologico dos dois é diferente. Já Platao afirmou a diferenca essencial entre o empírico temporário e arquetípico eterno, ideal mas parece que para Gambini a diferenca entre eles torna-se o ponto de partida para a crítica social e psicológica. Por isso critica "obra portuguesa" da colonização: "grande obra portuguesa ? Se não há reconhecimento do valor da miscigenação, onde está a grandeza ? No ato de procriar ? (...)" (DIAS, GAMBINI, 1999:77).

Segundo Gambini é aquele frequentemente mencionado caráter híbrido do Brasil uma característica muito superficial. Os brasileiros é uma nação "fracionada" e "dividida" onde prevalece o "medo do outro":

No plano do vísível, dizemos que somos um povo de diferentes, que se juntaram num mesmo caldeirão. Então é a imagem da sopa feita de vários ingredientes, onde se mistura tudo. Por baixo, no plano visível, é o contrário disso. Somos um povo fracionado e dividido (...) (GAMBINI, 1999:72).

A causa dessa superficialidade, desta síntese é o que Gambini denomina como "negação" ou "negaçôes" e que coloca no próprio início do período colonial. Segundo Gambini a síntese civilizatória ou cultural ou hibridização nunca aconteceu. A resistência a algo assim existiu nomeadamente entre os europeus católicos. O resultado disso é a enorme desproporção contemporânea entre as atitudes conscientes e o inconsciente coletivo brasileiro: 
(...) a sociedade brasileira está amarrada, mas não sintetizada. Pode-se juntar, passar um cordão em volta e dizer: "Olha aqui um conjunto de coisas". Mas não houve amálgama, nao houve síntese. Por quê? Porque há uma negação. Na hora de medir os valores, eles são muito desiguais. É nós sabemos que isso começa com a negação da alma do outro ( GAMBINI: 1999, p.68-69)

A raíz das disproporçôes da cultura brasileira é perceptível já no século XVI e tem sua origem nas projeçóes coletivas entre os índios e os portugueses. Justamente esse encontro não foi investigado como evento psicológico. Para Gambini isso é uma tarefa fundamental para a compreensão da identidade brasileira: "Quando digo que precisamos psicologizar o encontro do português com o indio, naquele momento que certamente náo foi 1500, mas não importa, naquele momento se constitui uma tarefa mítica. Psíquica e mitica, social e histórica" (DIAS, GAMBINI:1999, p.103). Psicologizar o encontro primário significa estudar, através dos documentos históricos e imaginário neles contido, a projeção:

(...) intensity of a projection is inversely proportionate to the opening of the conscious attitude. If the conscience obstinately fights against the emergency of an unconscious content, this may recur to drastic measures to be reorganized. (..) According to Jung, "the unconscious does it clearly through the projection, extrapolating its contents in an object, that then reflects on what was previously hidden in it". One of the best situations of this kind of unconscious expression arises when man faces the unknown, whether in another person, another culture (...), (GAMBINI: 2000, p.28)

O Brasil foi construído a partir do encontro do europeu com o "Outro", em outras palavras a partir da projeção coletiva. Foi justamente a projeção inicial coletiva que está no raíz da desproporção e do desequilíbrio da psicologia coletiva brasileira. $\mathrm{O}$ imaginário coletivo brasileiro, as mitologias brasileiras contemporâneas não correspondem com a realidade porque omitem uma grande parte do imaginário de várias partes da população brasileira:

O mito historiciza, trabalha com a passagem das gerações, simboliza estágios de transformação da cultura (...). Não são grandes figurações das transformações da consciência? (...), qual é a mitologização desse terrível drama histórico que é a colonização? Como a colonização se auto-representa miticamente? (...) o mito do Brasil hoje certamente não é indígeno, ele tem que ser um mito sincrético porque já é uma resultante (GAMBINI:1999, p.100-101).

Gambini não fala da omissão, mas da negação que, aliás, considera um padrão estabelecido já no século XVI quando, usando uma expressão de Darcy Ribeiro, “a pro- 
tocélula" da sociedade estava ganhando a sua forma. Já nas primeiras famílias protobrasileiras foi perceptível unilateralidade e negação das culturas, das tradiçóes, das religiōes indígenas. Um dos desequilíbrios foi o desequilíbrio entre masculino e feminino no sentido psicológico e cultural.

O primeiro brasileiro é filho de pai branco com mãe índia. (...) A protocélula da nossa sociedade é a junção desse primeiro homem com as índias (...). É esse o nosso pai ancestral. Não há estátuas, documentos ou fantasias sobre esse homem. Mas certamente não é um pai que se recomende. (...) Se a gente começar a pensar nas qualidades paternas e maternas que vão influenciar esse povo, veremos aí que já nascemos com sérios problemas. (...) Um menino brasileiro, filho do pai português e mãe tupinambá, não tinha lugar na corte quinhentista (...). Também não pertencia ao mundo da mãe. Ele não tem saída. Vai ficar num vazio (...). Comece a imaginar isso psicologicamente, em termos de criaçăo de uma identidade. (GAMBINI:1999, p.29-32)

\section{O feminino esvaziado e "aventura fálica"}

Outra razão da condiçấo contemporânea do consciente coletivo brasileiro decorre, segundo Gambini, do princípio feminino mal resolvido e mal colocado já no próprio início do período colonial. Mas não devemos pensar o feminino sem pensarmos o masculino porque esses dois arquetipos são complementares e formam uma união (coniunctio oppositorum). Segundo Gambini as representaçóes coletivas brasileiras revelam que a relação entre os dois é distorcida porque "no nível das representaçóes coletivas há um vazio no lugar da grande força heróica feminina. Isso é uma distorção porque, na realidade, essa força se exerce" (DIAS-GAMBINI:1999, p.45). Psicologia junguiana concebe "os homens e as mulheres de um país são duas polaridades arquetípicas, o sol e a lua, o yang e o ying" mas "no Brasil, a gente não sabe lidar com as polaridades" (DIAS-GAMBINI:1999, p. 45).

O feminino distorcido provém do primeiro encontro entre os homens europeus $\mathrm{e}$ as mulheres índias. Esse encontro gerou uma imaginação e uma projeção poderosa $\mathrm{e}$ inevitável. Consequentemente, a força e a intensidade dessa imaginação produziram a desproporção cultural e moral entre as duas culturas:

A mulher [do português], completamente reprimida, controlada, muito rígida, com comportamentos padronizados, ficou lá em Portugal. E não apenas ele vai encontrar uma mulher que é o seu pólo oposto, como há uma fantasia no meio. Que fantasia é essa? É a fantasia do Jardim do Éden, e Eva. (...) Ele está se sentindo como Adāo e vai ter a 
chance de transar com Eva (...) essa Eva é só corpo disponível. Um corpo sem alma (...) (DIAS-GAMBINI:1999, p. 40-41)

Por outro lado, há homem europeu, conquistador cuja atuação no Novo Mundo foi completamete masculina e justificada pela autoridade da igreja católica e do papado:

They were phallic adventures (...) ruled by the phallic principle of penetrating the unknown (...) [they] see Indian women, whose physical beauty (...) and being the way to projection of the Eve figure outlined beforehand (..), their lasciviousness was not only permitted but also stimulated by the maximum authority of the system (...). Hadn't Pope Alexandre VI pontificated that there was no sin South of the Equator? (GAMBINI:2000, p.166-167)

Na visão de Gambini o papel do lado masculino não foi somente desproporcionado em relação ao feminino mas também foi patológico. No ver dele é a masculinidade distorcida que é responsável pelo esvaziamento do feminino índio. Consequentemente, a complementaçáo dos opostos, o coniunctio oppositorum, nunca aconteceu. $\mathrm{O}$ masculino colonizador

(...) vira um perigo porque fica unilateral. Faltam-lhe atributos que vêm do feminino. Por exemplo, Eros: compaixão, afabilidade, espera, amabilidade, persistência, vinculação pessoal e grupal, relação com a natureza, com o sagrado ...(...) Aqui, é um homem que vai com um bando de outros homens, pegando mulheres pelo caminho, porque mulher não faltava. (DIAS-GAMBINI:1999, p. 32-33)

$\mathrm{O}$ exemplo de um modelo masculino assim seria segundo Gambini bandeirante. Ele constitui a extensão da "aventura fálica", é um aventureiro, "um homem com uma tropa atrás (...) não é o modelo do quaker americano, marido, mulher e uma enxada (DIASGAMBINI:1999, p.32). O lado contrasexual desse homem protobrasileiro representava o feminino índio que ficou reduzido somente ao aspecto biológico. Esse fato constitui a primeira negação na história brasileira. É o que Gambini chama de "o feminino esvaziado":

(...) ficará reduzida apenas à sua função biológica, porque, psiquicamente, ela não pode ser mãe. (...) Ela é mãe, mas aquilo que ela carrega como tradição não conta. Fechou-se a porta de volta. Então, ela não pode exercer a plena maternidade psíquica. (...) aquele filho não é uma continuação sua. (...) Ele vai ter que acreditar na doutrina católica. (...). $\mathrm{O}$ feminino se reduz à maternidade biológica e ao trabalho coadjuvante. Não há protagonismo. A índia, primeira mulher, não é mais sujeito da história, nem da própria vida (DIAS-GAMBINI: 1999, p.43). 
Os primeiros protobrasileiros sofreram grande desiquilíbrio psicológico justamente por causa da falta da feminilidade. Segundo Gambini valores associados com a feminilidade são carentes no Brasil: "valores como compaixão, afabilidade, sentimento, paciência, maleabilidade e capacidade de perdoar vêm do princípio feminino" (DIAS-GAMBINI:1999, p.31). Essa unilateralidade formou um caráter manco. O filho dos primeiros conquistadores não tem a mãe e a cultura maternal valorizada e sem isso "não sabe quem é, nem o que vale, nem qual é o seu lugar" (DIAS-GAMBINI:1999, p. 31)

A desproporção entre os polos arquetípicos foi seguida pela desproporção entre o elemento europeu, por um lado, e o elemento índio e africano por outro. Consequentemente as próprias bases da civilização brasileira sofrem por falta da verdadeira síntese:

Não sei o que é "mãe gentil". O arquétipo materno está muito mal, basta olhar o índice de mortalidade infantil. Falta emergir no Brasil o arquétipo da Grande Mãe, não "pátria amada, mãe gentil", mas a verdadeira mãe que zela por seus filhos e os alimenta, porque tem compaixão pelo sofrimento deles. No Brasil, um país de desigualdade, onde o problema da sobrevivência está sempre presente, qual é a energia das mulheres para levar isso adiante (DIAS-GAMBINI:1999, p.44-45)

Se o feminino brasileiro fica prejudicado pelo passado unilateral, o masculino continua a reproduzir o modelo historicamente programado. Segundo Gambini "a sociedade brasileira foi fundada, criada e mantida pelo princípio masculino, fálico, desbravador, penetrante, conquistador e impune em seus excessos" (DIAS-GAMBINI, p.175)

(...) famílias sem pai, lideradas por mulheres, é um problema enorme no Brasil. O pai ausente é um homem bêbado que não consegue lidar com a tremenda carga de ter que sustentar uma família, ter que ser responsável, ter um vínculo com aquela mulher e com aqueles filhos. A pinga é o combustível da não-ação (DIAS-GAMBINI:1999, p.164)

Para Gambini, a posição aparentemente segura e impressionante do homem brasileiro é o disfarce culturalmente programado de um ser fraco e "extremamente inseguro" que precisa "tantas defesas" e "tantos apoios", é "arcabouço malfeito que esconde um grande medo (...) de encontrar dentro de si uma coisa que contradiga aquilo que ele está afirmando" (DIAS- GAMBINI:1999, p.178).

A posteridade dos primeiros casais luso-brasileiros que não foi acolhida nem na cultura indígena nem na cultura portuguesa Gambini denomina "ninguéns". São eles que constituem psicologia que segue mais ou modelo do héroi nacional Macunaíma: 
O filho não tem as referências iniciais para poder viver sua individuação, descobrir-se a si mesmo e cumprir um destino. Macunaíma não ocupa um lugar na sociedade. Essa junção mal-resolvida de elementos diversos provenientes de três raças precisa de uma síntese. Mas ele não tem condições (...). Ele não chega ao fim do trajeto heróico. (DIAS-GAMBINI:1999, p.128-129)

Parece que as distorçóes acima referidas da sociedade brasileira influenciaram também a historiografia que, segundo Gambini, interpreta a historia nacional a partir da perspectiva puramente masculina: "Na nossa história é sempre o masculino que dita e faz - os desbravadores, os jesuítas, os bandeirantes, os empreendedores, os fazendeiros, são sempre os homens" (DIAS-GAMBINI:1999, p.176). Essa perspectiva "científica" é na verdade resultado do hábito inconsciente e por isso geralmente considerada "normal” mas essa "leitura da história é vesga porque dá primazia a um só lado" (DIAS-GAMBINI:1999, p.176). Em outras palavras, a leitura da história brasileira fica presa no complexo paternal coletivo.

A resolução deste assunto e desta unilateralidade Gambini vê no lado feminino dos homens, que foi evidentemente negado, violado, suprimido, desvalorizado. Claro que o problema constitui principalmente as imagens estereotipadas do homem brasileiro e da mulher brasileira. Para Gambini solução da desproporção entre o masculino e o feminino constitui em "detectar e definir os princípios no homem que foram negados", daí "surgirá uma leitura mais psicológica e mais profunda de nossa história e de suas perversidades e distorçóes” (DIAS- GAMBINI:1999, p.176).

\section{Complexo cultural e a tradição junguiana no Brasil}

O conceito do complexo cultural foi concebido pelo Thomas Singer e Samuel Kimbles e o conceito parecido de "inconsciente cultural" encontramos também em M. V. Adams e J. Henderson. Todos se referem à um gráfico da psique humana do Jung do ano 1928. O inconsciente cultural se refere à uma camada do inconsciente que se encontra entre o inconsciente pessoal e o inconsciente coletivo (natural). Vida psíquica dos coletivos grandes, é constituída tanto pelo consciente quanto pelo inconsciente. Enquanto disciplinas como história, sociologia, ciência política ou antropologia baseam as suas análises a partir dos produtos do consciente, psicologia junguiana se aproveita dos seus instrumentos tanto teoricos quanto práticos para entrar e decifrar a "caixa preta" do inconsciente cultural.

Durante maior parte da vida dele Jung prestou muito mais atenção a psique individual e que tocou a questão do complexo cultural só nos ensaios, na correspondência 
(JUNG:1975) e nas entrevistas (McGUIRE-HULL:1977). Assim os pós-junguianos apoiam-se principalmente dos estudos dele da teoria do complexo o que constituiu a primeira contribuição dele para a psicanálise incipiente. E hoje em dia essa teoria continua sendo uma peça-chave do que os pós-junguianos consideram inconsciente coletivo, teoria em que se basea o conceito do complexo cultural:

We define a cultural complex as an emotionally charged aggregate of historical memories, emotions, ideas, images, and behaviors that to cluster around an archetypal core that lives in the psyche of a group and is shared by individuals within that identified collective (SINGER: 2012, p. 5)

A escola pós-junguiana aplica a teoria do complexo do Jung ao nível cultural da psique. A abordagem do Jung foi muito redutiva porque Jung interpretava culturas puramente a partir do nível arquetípico.

Jung não elaborou nenhuma teoria da psicologia dos grandes grupos humanos, mas ficou bem consciente da existência do que hoje definimos como inconsciente cultural. Viajando para América, África e Ásia, ele se expunha às várias tradiçôes religiosas e discutia sobre as características nacionais. Por outro lado, era suspeitoso em relação aos grandes grupos e salientava o perigo para a psique individual de ser contaminada pela psique coletiva. Consequentemente Jung teve tendência separar a evoluçáo da psique individual e da psique coletiva. Vivenciando duas guerras mundiais o psicólogo ficou consciente do perigo da contaminação da psique individual pelos complexos coletivos e por isso punha enfâse ao indivíduo e a importância da introversão. Segundo Singer e Kimbles foram essas atitudes que refletiam a experiencia dele com os movimentos de massa na época da primeira metade do século XX e foram essas mesmas atitudes que, pouco a pouco, criaram a "sombra" não reconhecida junguiana (SINGER-KIMBLES:2004, p.4). Geração pós-junguiana está adquirindo aos poucos uma distância crítica do maître dela, abre-se às análises dos coletivos maiores e também à interdisciplinaridade.

\section{Conclusão: Alma além da "realidade" e da "fantasia"}

Tanto como termo quanto como conceito "a alma" fica fora das correntes principais da história das ideias do século XX. Até quando os autores querem falar sobre a alma preferem usar expressóes que parecem mais científicas como "psique". "A alma" ainda sobrevive na língua coloquial como façon de parler, mas a psicologia moderna não pode dedicar-se ao estudo da alma imaterial, da faísca divina imortal do ser humano: 
Modern psychology can be concerned with the feelings, emotions, wishes, desires, drives, ideas, experiences, traumas, symptoms, dreams, etc., of natural, empirical, finite man, bodily existing man, mas as positive fact. It cannot entertain the notion of an immaterial soul substance as the infinite, divine core of man (...) (GIEGERICH: 2012, p.14)

O processo de eliminação do conceito de alma do pensamento e do imaginário ocidental correspondeu com o processo de secularização. Esse processo ficou cada vez mais evidente durante o século XIX. A filosofia daquela época eliminou pouco a pouco o conceito tradicional de alma e hoje até as disciplinas como teologia e psicologia o evitam. Enquanto Nietzsche declarou a morte de Deus, Friedrich Albert Lange em sua obra Geschichte des Materialismus (História do materialismo, 1866) falou sobre "Psychologie ohne Seele” (psicologia sem alma). Ambas declaraçôes foram só manifestaçôes do espírito da época (GIEGERICH:2012, p.7-8)

Foi Jung quem começou a questionar o programa da "Psychologie ohne Seele" do Lange. Pensamento de Jung não correspondeu com o espírito da época: Jung defendeu a "Psychologie mit Seele" (psicologia com a alma), programa oposto do que sugeria Lange. A idéia de Jung foi na verdade baseada na idéia da mente autônoma. Uma hipótese assim foi escandalosa porque se opunha ao positivismo teórico. Na tradição cristã a alma foi entendida como um polo do coniunctio oppositorum do corpo-alma:

(...) in the Christian tradition, the soul was essentially (...) what people's vital concern for "eternal salvation" and the fear of "eternal damnation" circled around. (...) By contrast, the human body was the visible, empirical but mortal, perishable aspect of man. The body-soul pair thus meant that human existence as a whole was comprehended as coniunctio oppositorum (...) (GIEGERICH:2012, p.15)

Mas C.G. Jung, e depois dele James Hillman começaram a "ler a alma” no contexto histórico e social e a tese principal dessa leitura, aliás, assumida também pelo Gambini, é que a alma fala de si mesma constantemente através das imagens a essa fala dela é perceptível na criação e atuação humana, i.e. na poesia, música, literatura, mitologia, arquitectura, urbanismo, organização social e política, nas ciências, cinematografia, na "fala do corpo" etc. Tudo o que percebemos, entendemos tem na essência o caráter arquetípico, i.e. imaginal:

(...) the fundamental facts of existence are the "fantasy-images" of the psyche. All consciousness on these depends. Everything else - ideas of the mind, sensations of the body, perceptions of the world around us, beliefs, feelings, hungers - must present themselves as images in order to become experienced. "'Experience' is, in its most simple form, an exceedingly complicated structure of mental images." (HILLMAN:1975, p.22-23) 
Como analista da alma brasileira, Gambini chama atenção ao papel importante da arte para a compreensão e o conhecimento da alma do país dele. Mas também sabe que a autenticidade e o amor fati (amor pelo destino) que a alma requer é sutil demais para o consciente coletivo da nossa época. Em vez disso, o consciente coletivo brasileiro é regido pelos inúmeros padrôes autodestrutivos. A alma não é reconhecida e é sistematicamente rejeitada o que é melhor visível nas imagens artísticas:

Eu percebo uma profunda tristeza no Brasil, acompanhada de alegria e de vontade de viver. O Brasil tem muita energia vital, mas tem uma tristeza enorme. Basta olhar para as imagens que os artistas fazem do país para perceber essa tristeza oculta (...), mas que a gente abafa, disfarçando (...). Tentamos nos convencer disso para não deixar essa tristeza falar. (...) Cada uma das barbaridades que acontecem a cada dia, as barbaridades brasileiras, o bárbaro que impera no Brasil (...) (DIAS- GAMBINI:1999, p.75)

A perspectiva assumida pela psicologia arquetípica/imaginal contribuiu significativamente à desconstrução da visão da separação radical entre o mundo exterior/ objetivo e o mundo interior/subjetivo do sujeito da filosofia moderna. C.G. Jung, James Hillman e todo conceito junguiano da "Psychologie mit Seele" corresponde com as descobertas científicas (Albert Einstein, Werner Heisenberg por exemplo), na teoria das ciências (Karl Paul Feyerabend, Fritjof Capra) e nas formas científicas alternativas (Stanislav Grof, Terence McKenna, Richard Tarnas, Rupert Sheldrake e outros). Assim, "vivemos no mundo que nem é 'interior' nem 'exterior":

In the beginning is the image; first imagination then perception; first fantasy then reality. (...) Since we can know only fantasy-images directly and immediately, and from these images create our worlds and call them realities, we live in a world that is neither "inner" nor "outer". Rather the psychic world is an imaginal world, just as image is psyche. Paradoxically, at the same time these images are in us and we live in the midst of them. (HILLMAN:1975, p. 23)

A mesma perspectiva encontramos em Gambini quando escreve sobre a alma brasileira cuja conscientização, compreensão e assimilação considera possível através das imagens coletivas. Para o autor, "É preciso entrar em contato com esses conteúdos que estáo adormecidos dentro de cada um de nós (...). Está na hora de fazer uma revisão psicológica da história do Brasil" (DIAS-GAMBINI:1999, p.92-93).

Desde sempre a dimensão arquetípica do ser se manifestava através do imaginário. Qualquer encontro com o desconhecido, não investigado, misterioso contem uma grande carga do imaginário arquetípo que é frequentemente difícil de resolver para o 
ego. Durante a história o caráter arquetípico dessas imagens continua o mesmo. O que muda e se transforma é só a forma metafórica através da qual o homem as entende. Isso se aplica até as categorias cientificas e a linguagem científica porque "all ways of speaking of archetypes are translations from one metaphor to another. Even sober operational definitions (...) are no less metaphorical than an image which presents the archetypes as root ideas, psychic organs, figures of myth (...)” (HILLMAN:1975, p. XIII).

Os arquetipos ou as imagens arquetípicas dominam as vidas humanas individuais e coletivas em todos os aspectos, regem a nossa compreensão do mundo, da nossa vida interior e exterior, nos ligam tanto ao passado quanto ao futuro. Também os navegadores portugueses e os índios brasileiros foram regidos pelas imagens mais ou menos padronizadas pelas suas respectivas tradiçóes que inconscientemente projetaram para "o Outro". Da perspectiva junguiana, esse encontro fazia parte da evoluçáo universal da anima mundi que, no Brasil e em outros lugares do mundo, levou ao drama psico-histórico. Mas resolver uma situação assim pela mistura ideal, i.e. coniunctio oppositorum era provávelmente impossível. Mas é certo que esses eventos contribuiram à transformação da tradição religiosa cristã europeia. David Tacey fala de "the alchemical meltdown of religious forms" e destaca que "instead of focusing on the historical Jesus, Jung encourages post-traditional Christians to discover the cosmic Christ at the centre of their being" (TACEY:2007, p. 3). Um dos fenômenos que nos liga com os acontecimentos do século XVI é justamente a diluição das formas religiosas. Enquanto o cristianismo tradicional não gosta da ênfase psicologica à vida interior humana porque "they are unable to concede that there could be an element of the divine in human nature, and they believe that our nature cannot be trusted and is inherently flawed and sinful" Jung insistiu que "the relationship with the redeemer can be found through inner experience, and does not have to be mediated by Church or institution" (TACEY:2007, p.3-4). A ênfase posta na experiência interior do divino foi exatamente o que o século XVI vivenciou através do surgimento do protestantismo.

Desde os anos 60 do século XX vivenciamos algo muito parecido com o surgimento do New Age e com os processos da globalização, da migraçáo global, da diluição das formas tradicionais da convivência e das novas formas de espiritualidade. Neste contexto, a redescoberta da alma é o sinônimo da vida interior autêntica, uma volta para a ideia da faísca divina dentro do ser humano individual. Talvez um contexto assim seja propício para coniunctio oppositorum também no Brasil, auxiliando em pressupostos de uma memória crivada por oposiçóes suplementares, como é a problemática da oralidade e da escrita que nos remete ao texto fragmentário da nossa constituição identitária 


\section{$\operatorname{son}$}

\section{NOTAS}

1 Daryle Williams menciona as duas exposiçóes que foram apresentadas nos EUA e que deram origam ao conceito das culture wars: 1) exposição planejada do fotógrafo Robert Mapplethorne na Corcoran Gallery em Nova Yorque (1989) conhecida como Robert Mapplethorne: The Perfect Moment, 2) exposição Enola Gay (1995) no National Museum of Air and Space, o ramo do Smithsonian Institution (WILLIAMS:2001, p. 22).

2 Volume 14/1: Mysterium Coniunctionis - Os componentes da Coniunctio; Paradoxa; As personificaçóes dos opostos. Volume 14/2: Mysterium Coniunctionis - Rex e Regina; Adão e Eva; A Conjunção. Volume 14/3: Mysterium Coniunctionis - Epílogo; Aurora Consurgens.

\section{REFERENNCIAS}

ADAMS, Michael Vannoy. Fantasy Principle. The Psychoanalysis of the Imagination. London-New York: Brunner-Routledge 2004.

ADAMS, Michael Vannoy. The Multicultural Imagination. "Race", Color, and the Unconscious. London-New York: Routledge 1996.

EDINGER, Edward F. “The New Myth of Meaning”. Quadrant, vol. 10. n 1, summer 1977, pp. 23-38.

GAMBINI, Roberto. Indian Mirror. The Making of the Brazilian Soul. São Paulo: Axis Mundi/Terceiro Nome, 2000.

DIAS, Lucy GAMBINI, Roberto. Outros 500. Uma conversa sobre a alma brasileira. São Paulo: Senac 1999.

GAMBINI. Roberto. “The Challenge of Backwardness”. In: CASEMAN, Ann (ed.). Post-Jungians Today. Key Papers in Contemporary Analytical Psychology. London-New York: Routledge, 1998, pp. 149-163.

GIEGERICH, Wolfgang. What is Soul? New Orleans, Louisiana: Spring Journal Books 2012.

HILLMAN, James. Re-Visioning Psychology, New York: Harper \& Row, 1975.

JUNG, C. G. Briefe I-III. Zürich: Walter Verlag AG, 1975.

JUNG, Carl Gustav. Collected Works, vol. 13 (Bollingen Series XX). Princeton, N.J.: Princeton University Press/London: Routledge and Kegan Paul, 1953.

ROWLAND, Susan (ed.). Psyche and the Arts. Jungian Approaches to Music, Architecture, Literature, Painting and Film. London-New York: Routledge 2008.

SINGER, Thomas - KIMBLES, Samuel. The Cultural Complex. Contemporary Jungian Perspectives on Psyche and Society. London: Brunner-Routledge 2004.

SINGER, Thomas (ed.). Listening to Latin America. Exploring Cultural Complexes in Brazil, Chile, Colombia, Mexico, Uruguay, and Venezuela. New Orleans, Louisiana: Spring Journal Books, 2012.

TACEY, David. After Tradition: Closer Encounters With the Sacred. London: The Guild of Pastoral Psychology, 2007.

WILLIAMS, Daryle. Culture Wars in Brazil: The First Vargas Regime (1930-1945). Durham-London: Duke University Press, 2001. 


\section{Resumo}

Este artigo tem como seu ponto de partida algumas teses fundamentais da psicologia arquetípica, teses desonvolvidas por C. G. Jung e na virada dos anos 1960 e 1970 extensivamete desenvolvidas pelo James Hillman: 1) a imagem como manifestação primária e viva da psique e não como conceito teórico, 2) a necessidade do mito cultural vivo de cada comunidade humana, 3) a consciência como titular das polaridades (oposiçóes). Estas três teses podem servir como ponto de partida para a interpretaçáo do encontro histórico da cultura europeia/portuguesa do século XVI e da cultura das tribos indígenas brasileiras e por isso também para a interpretação da cultura contemporânea brasileira. São justamente essas teses que formam a base do pensamento do analista Roberto Gambini. Este estudo pretende apresentar o pensamento de Gambini sobre a identidade e a alma brasileira e referir-se as outras perspectivas junguianas abertas por conceito recente do "complexo cultural" e como é aplicado nas condiçôes brasileiras.

\section{Abstract}

This paper's point of departure is constituted by three fundamental theses of archetypal psychology developed by C. G. Jung and later, in the turn of 1960s and 1970s, extended by James Hillman: 1) image as a rather primary and vital expression of the psyche and not as a theoretical concept, 2) necessity of a cultural myth for human community, 3) human consciousness as a carrier of polarities. These three theses serve as a basis for an interpretation of cultural encounter betweem Europeans/Portuguese and indigenous inhabitants of 16th-century Brazil and constitute a basis of Brazilian analyst Roberto Gambini's thought. Introducing Gambini's thought about Brazilian identity and soul, the paper also refers to other Jungian perspectives open to contemporary concept of "cultural complex" and its application to Brazilian conditions.

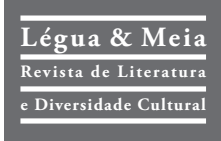

VRBATA, Aleš. Memória Ancestral e o Brasil contemporâneo - Tradição junguiana e o inconsciente brasileiro. Légua \& Meia: Revista de literatura e diversidade cultural. Feira de Santana: UEFS, A. $14, \mathrm{n}^{\mathrm{o}}$ 7, 2016, p 158-174.

Aleš Vrbata é PhD em história pela Universidade Carolina, Praga, Rep.Tcheca (2010), pósdoutorando (CAPES/PNPD) na UEFS/PROGEL, Feira de Santana, Bahia, sob a orientaçáo do professor Claudio C. Novaes. Membro do NEC (Núcleo de Estudos Canadenses) e do CELFCAAM (Centro de Estudos em Literaturas e Culturas franco-afro-americanas) e ESSWE (European Society for the Study of Western Esoterism). 